\title{
On 'being first': the case for first-generation status in Australian higher education equity policy
}

\author{
Sally Patfield ${ }^{1}$ (D) . Jennifer Gore ${ }^{1}$ (D) $\cdot$ Natasha Weaver $^{2}$ (D)
}

Received: 13 September 2020 / Accepted: 26 December 2020 / Published online: 6 February 2021

(c) The Author(s) 2021

\begin{abstract}
For more than three decades, Australian higher education policy has been guided by a national equity framework focussed on six underrepresented target groups: Indigenous Australians, people from low socioeconomic status backgrounds, people from regional and remote areas, people with disabilities, people from non-English speaking backgrounds, and women in non-traditional areas of study. Despite bringing equitable access to the forefront of university agendas, this policy framework has fostered a somewhat narrow conceptualisation of how educational disadvantage should be addressed. Responding to calls for reform, this paper draws on survey data from 6492 students in NSW government schools to examine the extent to which a new category warrants inclusion in the national framework: first-generation status. We illustrate how being the first in a family to attend university brings distinct equity status and argue for a revision of the national equity framework to recognise and support students who are 'first'.
\end{abstract}

Keywords First-generation · First-in-family status · Equity · Higher education · University $\cdot$ Widening participation

\section{Introduction}

In recent decades, student equity in Australian higher education has been framed by a discourse of underrepresentation. Located within the broader policy agenda of 'widening participation', this discourse first emerged alongside the federal government's positioning of higher education as an important driver of economic prosperity and a critical mechanism in enhancing social justice (Department of Employment, Education and Training 1990). Framed within this context, the premise behind

Sally Patfield

sally.patfield@newcastle.edu.au

1 School of Education, University of Newcastle, University Drive, Callaghan, NSW 2308, Australia

2 School of Medicine and Public Health, University of Newcastle, Newcastle, Australia 
this discourse has been twofold. First, 'underrepresentation' reflects an interest in identifying and supporting socio-demographic groups that have historically low rates of university enrolment (Pitman 2017), as well as being socially, economically, and/or educationally disadvantaged (Coates and Krause 2005). Second, 'underrepresentation' foregrounds government objectives to reduce inequality in higher education access and participation for marginalised groups, with policy and practice built around a belief that equity will be achieved once proportional representation is met (Harvey et al. 2016).

This discourse is particularly evident in the national equity framework, which has long focussed on six disadvantaged groups underrepresented in higher education: people from low socioeconomic status (SES) backgrounds, Indigenous Australians, people from regional and remote areas, people with disabilities, people from non-English speaking backgrounds (NESB), and women in non-traditional areas of study. Originally released in 1990 as part of a landmark federal government discussion paper, A Fair Chance for All (Department of Employment, Education and Training 1990), this framework continues to shape how equity is understood, funded, and addressed in the present day. Performance data for each group are collected and reported annually at various levels of granularity. The vast majority of equity interventions are directed at these groups in the name of improving access (Bennett et al. 2015), although some universities do target other equity groups through institutional-level initiatives. And, most research on equity in higher education focusses on students who belong to one or more of these groups, helping to provide an evidence base for policy and practice (see, for example, Bok 2010; Harwood et al. 2015; Hawkins 2014). In this way, 'underrepresentation' names a problem in need of fixing but, in general, only the participation of these six groups is recognised as problematic.

Arguably, such a focussed approach to addressing equity has many advantages. In particular, the longevity of the national equity framework (30 years at the time of writing) has generated longitudinal data for tracking access, participation, success, and retention rates across time for each group (Coates and Krause 2005). For example, almost 20 years after A Fair Chance for All, a major review of the higher education sector used these data to pinpoint three disadvantaged groups as still 'seriously under-represented': Indigenous Australians, people from low SES backgrounds, and Australians living in regional and remote areas (Bradley et al. 2008)-disparities that persist in the present day (Koshy 2019). In comparison, the participation rates of people from NESB have actually increased (Bradley et al. 2008). The national equity framework has, therefore, provided a robust foundation on which to continually shape higher education policy and practice (Harvey et al. 2016) although, as yet, no major changes have been made to the framework informed by such findings.

Conversely, there are several shortcomings to this approach. In particular, longstanding issues with the operational definition of the equity groups has produced debate about how to quantify SES (Gale and Parker 2013) and who to include in the NESB category (James et al. 2004). Indeed, the federal government admits that defining and labelling equity groups was a difficult task in developing A Fair Chance for All (Department of Employment, Education and Training 1990), but essential given that measuring disadvantage - in its various forms - is the essence of 
any equity agenda (Coates and Krause 2005). Questions have also been raised about the six groups chosen for inclusion in the framework, given that the enduring preoccupation with these categories means that other groups have been ignored and overlooked (Harvey et al. 2016; Pitman 2017). As Harvey et al. (2016) succinctly put it, the designation of the six equity target groups was based on enrolment patterns in the late 1980s and, while the university sector has since changed dramatically, the way equity is conceptualised at a national level has essentially not changed at all.

In this paper, we enter this ongoing conversation by exploring a new category for inclusion in the national equity framework: first-generation status. While there are nuances in the definition of this category, the label is commonly used to refer to individuals who do not have a parent/carer with a university-level qualification (Spiegler and Bednarek 2013). As such, this category represents a mechanism by which to identify people without a family history of higher education-those who are 'newcomers' to university (Jehangir 2010). In recent years, first-generation status has been gaining traction among equity researchers and practitioners in Australia (Patfield et al. 2020a). However, local research examining this population is sparse (see, for example, Luzeckyj et al. 2017; O'Shea 2015; O'Shsea et al. 2017), particularly when compared to the volume of research from the United States (US), where the category originates and has underpinned higher education equity policy for decades. Given significant differences between Australia and the US, rigorous analysis is warranted if a compelling case is to be made for including this category in the Australian equity framework.

In order to evaluate the viability of first-generation status as an official equity target group, we systematically used Coates and Krause's (2005) three proposed approaches to ascertaining whether any new groups warrant inclusion:

First, an exploratory empirical approach could be used to identify groups of students which fall outside the current framework yet are under-represented in higher education. Second, new groups may arise as composites of the current groups, as a consequence of students belonging to more than one group and having overlapping or multiple memberships. Third, it is possible that there are entirely new ways of defining disadvantaged individuals and groups suggested by insights from research or practice. (p. 37)

In this paper, we utilise each of these approaches to interrogate first-generation status as a possible equity category. We begin by addressing the first approach described above, which establishes a rationale for even considering first-generation status and sets the scene for the empirical research to follow.

\section{Why consider first-generation status as an equity category?}

At face value, levels of enrolment for first-generation students in Australian higher education do not appear to be particularly problematic. According to data from the OECD (2012), 51\% of young people enrolled in Australian universities are first-generation students, a figure that has led some scholars to argue that we are now in the 
'era' of the first-generation student (O'Shea et al. 2015). Internationally, first-generation students have similarly been described as 'the new majority' in higher education (Jehangir 2010), with the OECD mean of first-generation enrolment share similarly being around 52\%. Arguably, these data reflect both the expansionist agenda and social justice motives of many higher education systems around the world, which have played a major role in opening a university pathway to 'newcomers'.

However, a fine-grained analysis of enrolment data suggests a much more worrying picture of first-generation entry, with higher education participation continuing to be dominated by those with a family history of university. The same dataset from the OECD (2012) shows that while 49\% of university attendees (aged 20-34 years) in Australia have at least one parent with a bachelor-level degree or higher, only $27 \%$ of the wider adult population hold a university qualification. If we had population parity, the enrolment share for first-generation students should stand around $73 \%$, not $51 \%$. At present, then, the odds of being enrolled in higher education are almost two times greater for individuals with a parent who holds at least a bachelor-level qualification (OECD 2012), starkly demonstrating the underrepresentation of firstgeneration students in the Australian higher education sector.

Beyond this quantitative measure of underrepresentation, first-generation students also experience educational disadvantage associated with 'being first'. While continuing-generation students - those with parental experience of university - have access to valuable cultural and social 'know-how' derived from their family histories, first-generation students often experience profound silences surrounding higher education-not only within their families, but within their communities (O'Shea 2015; Patfield et al. 2020a). What lies at the heart of first-generation status is therefore the relatively new and uncharted territory that pursuing higher education represents. Indeed, some first-generation students can initially see themselves as unsuitable for university (O'Shea et al. 2017) and, even after they enrol, feel that they are in another world (Meuleman et al. 2014). It is not surprising, then, that it can be more conceivable for first-generation students to follow in their parents' footsteps (O'Shea 2014). As such, when they do aspire - and go-to university, they are essentially disrupting their family history, an experience which can engender an intense emotional burden, particularly when family members see this pathway as threatening the anticipated life course (O'Shea et al. 2017). However, in this light, first-generation students can also be thought of as educational trailblazers (O'Shea et al. 2017), breaking down barriers so that others can follow in their footsteps (King et al. 2015).

Collectively, these quantitative and qualitative components of equity start to paint a picture of why first-generation status constitutes an important equity category outside the focus of the current national framework. Based on this evidence, we contend that the first of the three approaches from Coates and Krause (2005) is satisfied: not only are first-generation students underrepresented in Australian higher education, but they experience a form of educational disadvantage that currently falls outside of the national equity framework. However, additional evidence is required in order to advocate for first-generation status being included in the national equity framework, and so we turned our attention to teasing out this evidence by specifically focussing on the second and third approaches. We did so by drawing on our own empirical research investigating prospective 
first-generation students; young people enrolled in primary and secondary school who would be of the first generation in their families to attend university. This methodological approach makes a unique contribution to the literature, providing early insight into how educational disadvantage can manifest well before the point of entry into higher education, when young people begin to imagine and navigate their post-school futures.

\section{Methods}

We drew on survey data from a large-scale project examining the formation of post-school aspirations among students enrolled in government schools in the state of New South Wales (NSW), Australia. Funded by the Australian Research Council and the NSW Department of Education (DoE), this four-year project ran from 2012 to 2015 and used a cohort-sequential or accelerated longitudinal design to purposively sample four cohorts of students annually. In 2012, students were enrolled in Years 3, 5, 7 and 9-forming Cohorts 1-4 respectively-and were followed until they were in Years 6, 8, 10 and 12 in 2015.

Overall, 10,543 survey responses were received from 6492 students over the four waves. Surveys were administered online via SurveyMonkey, utilising standing consent for student participation. This means that each school had consent arrangements in place for students to participate in low-risk research, with parents/carers able to withdraw their children from the study at any time. Students and parents/carers were informed of the research via information packs, posters, and newsletters. In addition, the DoE provided enrolment data for each student, as well as their most recent results from the National Assessment Program Literacy and Numeracy (NAPLAN).

At the school level, the sample involved 64 government schools. Based on the Index of Community Socio-Educational Advantage (ICSEA), publicly available on the MySchool website, these schools are fairly representative of socio-educational advantage, with the mean ICSEA being 954 (with a standard deviation of 116). This is in comparison to the mean ICSEA of all Australian schools being 1000 (standard deviation 100).

At the student level, we used school enrolment data to categorise students as either 'first-generation' or 'continuing-generation', based on the highest level of education recorded for their parents/carers. First-generation status was assigned to students who did not have a parent/carer with a bachelor-level degree or higher, while continuing-generation status was assigned to students with at least one parent/ carer with a bachelor-level degree or higher. This approach aligns with the prevalent definitions in the literature, although we note that variations exist (Spiegler and Bednarek 2013). Based on this categorisation, 6704 survey responses were received from students who were classified as prospective first-generation, and 2911 received from continuing-generation students. Parental education was missing from 928 survey responses, which meant that these responses could not be used in the analysis. 


\section{Measures for analysis}

An overview of each measure included in the analysis is provided in Table 1, together with the operationalisation of each measure and its source.

In order to examine how first-generation status intersects with the current equity target groups, we compared the socio-demographic profile of prospective first-generation students in our sample to that of their continuing-generation peers. The socio-demographic measures of interest here were: sex, Indigenous status, language background, location, and ICSEA. Three of these variablesIndigenous status, language background, and location-directly align with the respective categories from the current national equity framework. The remaining two variables require further explanation. First, given that we do not have access to students' residential addresses, school ICSEA was used as a proxy for SES. Notably, ICSEA reflects the communities where students live aggregated to the school level and so captures (dis)advantage at an area-rather than individual level-similar to the national higher education equity framework. Second, because the equity category of 'women in non-traditional areas of study' relies, in part, on actual course enrolment data, our analysis of young people well before the point of access to university is restricted to examining sex. It is also important to point out here that the NSW DoE was not able to provide information on disability status, so this aspect of equity was unable to be investigated for this paper.

To test whether first-generation status represents an entirely new way to define educational disadvantage, we examined first-generation status as a predictor of university aspirations. Here, we construct aspirations as an indicator of how young people develop and construct a sense of their futures, or future selves (Archer et al. 2013), and thus whether they might see themselves as a university student (or not). Educational aspirations were derived from the student survey, which asked respondents to indicate the highest level of education they planned to complete. Responses were categorised as high school, Technical and Further Education (TAFE), university, or 'I don't know yet'. Independent explanatory variables were aligned with the current equity categories, and also incorporated other markers of (dis)advantage included in similar studies of young people's aspirations (Gore et al. 2017, 2018).

\section{Analysis}

A generalised estimating equation (GEE) approach was employed for all inferential analyses. GEEs are a robust analytical technique extending upon generalised linear models and quasi-likelihood methods, estimating consistent and unbiased regression parameters accounting for data being collected within subjects, across time (Ballinger 2004; Zeger et al. 1988). For this analysis, GEEs are appropriate given the: (1) clustering of observations, (2) varying number of observations over the four waves of data collection (for students who did not complete all four surveys or did not complete a survey each year), and (3) correlation of outcomes 


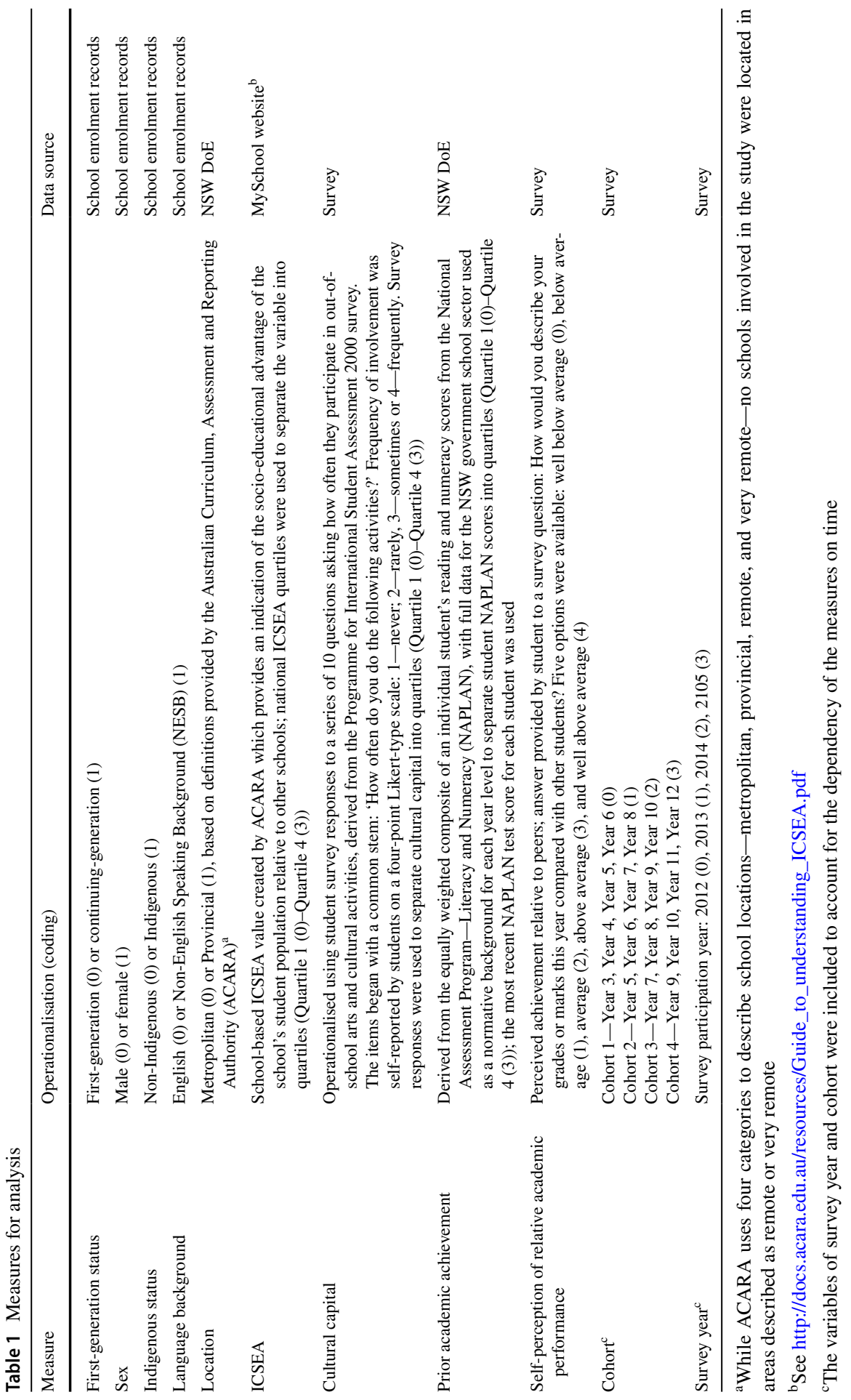


within students due to repeated measures for participants who responded to the survey on more than one occasion.

For the socio-demographic profile of first-generation students, the univariate association between the variables of interest and the dependent variable of first-generation status was examined using a GEE approach. Descriptively, we also mapped the intersection between first-generation status and the four measures most closely aligned with the existing equity categories: identifying as Indigenous; NESB; living in a provincial area; and, being from a lower SES background, as represented by the lower two ICSEA quartiles. We used Venn diagrams to visually illustrate the relationships between each of these four socio-demographic measures, separately for prospective first-generation students and continuing-generation students.

Next, to analyse educational disadvantage, independent variables were examined in relation to the binary outcome of university aspirations (yes/no). First-generation status was initially analysed separately from other independent measures through univariate logistic regression, and subsequently examined in the presence of other independent variables within a logistic regression model fitted within a GEE framework. All analyses were undertaken using SAS software version 9.4 and statistical significance was set at $p<0.05$.

\section{Results}

\section{A profile of prospective first-generation students}

We found evidence to suggest that prospective first-generation students are more likely to belong to one of the existing equity categories compared to their continuing-generation peers. As shown in Table 2, the significant socio-demographic variables were: Indigenous status, language background, and ICSEA. Specifically, prospective first-generation students were more likely to: identify as Indigenous $(p=.001)$, come from an English-speaking background $(p=.002)$, and come from a lower SES background, represented by school ICSEA $(p=.018)$. No statistically significant differences were found for sex or geographic location, although a much higher proportion of prospective first-generation students came from a regional or remote area.

When examining the raw survey responses, we also found that many prospective first-generation students had overlapping, or multiple memberships, with the existing equity categories. The two Venn diagrams visually illustrate the relationship between first-generation status (Fig. 1) or continuing-generation status (Fig. 2) with the socio-demographic variables of interest: Indigeneity; NESB; living in a provincial area; and, being from a lower SES background. These analyses used only the survey responses where all four measures were known.

To help interpret these diagrams, each ellipse represents one equity category as labelled: Indigeneity, low SES, provincial, NESB. Overlapping regions between ellipses denote intersections between two or more equity categories, while the single regions denote junctures between first/continuing-generation status and one equity category only. Each of the regions within an ellipse indicates the raw number of survey 
Table 2 Characteristics of first-generation and continuing-generation students

\begin{tabular}{|c|c|c|c|c|c|}
\hline \multirow[t]{2}{*}{ Variable } & \multicolumn{2}{|c|}{$\begin{array}{l}\text { First-Gen } \\
(n=6704)\end{array}$} & \multicolumn{2}{|c|}{$\begin{array}{l}\text { Continuing-Gen } \\
(n=2911)\end{array}$} & \multirow[t]{2}{*}{ Adjusted $p$-value } \\
\hline & $n^{\mathrm{a}}$ & $(\%)^{\mathrm{b}}$ & $\overline{n^{\mathrm{a}}}$ & $(\%)^{b}$ & \\
\hline Sex & & & & & 0.359 \\
\hline Male & 3388 & $(50.5)$ & 1477 & $(50.7)$ & \\
\hline Female & 3316 & $(49.5)$ & 1434 & $(49.3)$ & \\
\hline Indigenous status & & & & & 0.001 \\
\hline Non-Indigenous & 6131 & $(91.6)$ & 2843 & $(97.9)$ & \\
\hline Indigenous & 561 & $(8.4)$ & 61 & $(2.1)$ & \\
\hline Language background & & & & & 0.002 \\
\hline English & 6290 & $(93.8)$ & 2279 & $(78.3)$ & \\
\hline $\begin{array}{l}\text { Non-English speaking } \\
\text { background }\end{array}$ & 414 & $(6.2)$ & 632 & $(21.7)$ & \\
\hline Location & & & & & 0.507 \\
\hline Metropolitan & 3484 & $(52.0)$ & 2207 & $(75.8)$ & \\
\hline Provincial & 3220 & $(48.0)$ & 704 & $(24.2)$ & \\
\hline ICSEA & & & & & 0.018 \\
\hline Quartile 1 & 2027 & $(30.2)$ & 251 & $(8.6)$ & \\
\hline Quartile 2 & 3328 & $(49.6)$ & 645 & $(22.2)$ & \\
\hline Quartile 3 & 661 & $(9.9)$ & 257 & $(8.8)$ & \\
\hline Quartile 4 & 688 & $(10.3)$ & 1758 & $(60.4)$ & \\
\hline
\end{tabular}

${ }^{\text {a }}$ Survey responses

${ }^{\mathrm{b}}$ Percentages rounded to one decimal place. Percentages may not add to $100 \%$ due to rounding

${ }^{\mathrm{c}}$ Adjusted for repeated measures on Student Registration Number

responses, and accompanying percentage, for each intersection; for example, for prospective first-generation students, low SES $\bigcap$ Indigenous $=\{2.8 \%\}$; and low SES $\bigcap$ Indigenous $\bigcap$ provincial $=\{4.9 \%\}$. The Venn diagrams demonstrate all possible relationships between first/continuing-generation status and the equity categories of interest.

Overall, these descriptive results show that the vast majority of survey responses received from prospective first-generation students intersected with at least one of the existing equity categories (88\%), in comparison to continuing-generation students $(55 \%)$. Similarly, a higher proportion of responses from prospective first-generation students intersected with two or more of the equity categories. For instance, low SES $\bigcap$ provincial $=\{39.7 \%\}$ for prospective first-generation students, while the same intersection for continuing-generation students is low SES $\bigcap$ provincial $=\{18.6 \%\}$.

\section{First-generation status and educational aspirations}

Descriptively, the most popular educational aspiration for prospective first-generation students was 'university' (42.5\%), followed by 'don't know' (24.3\%), 


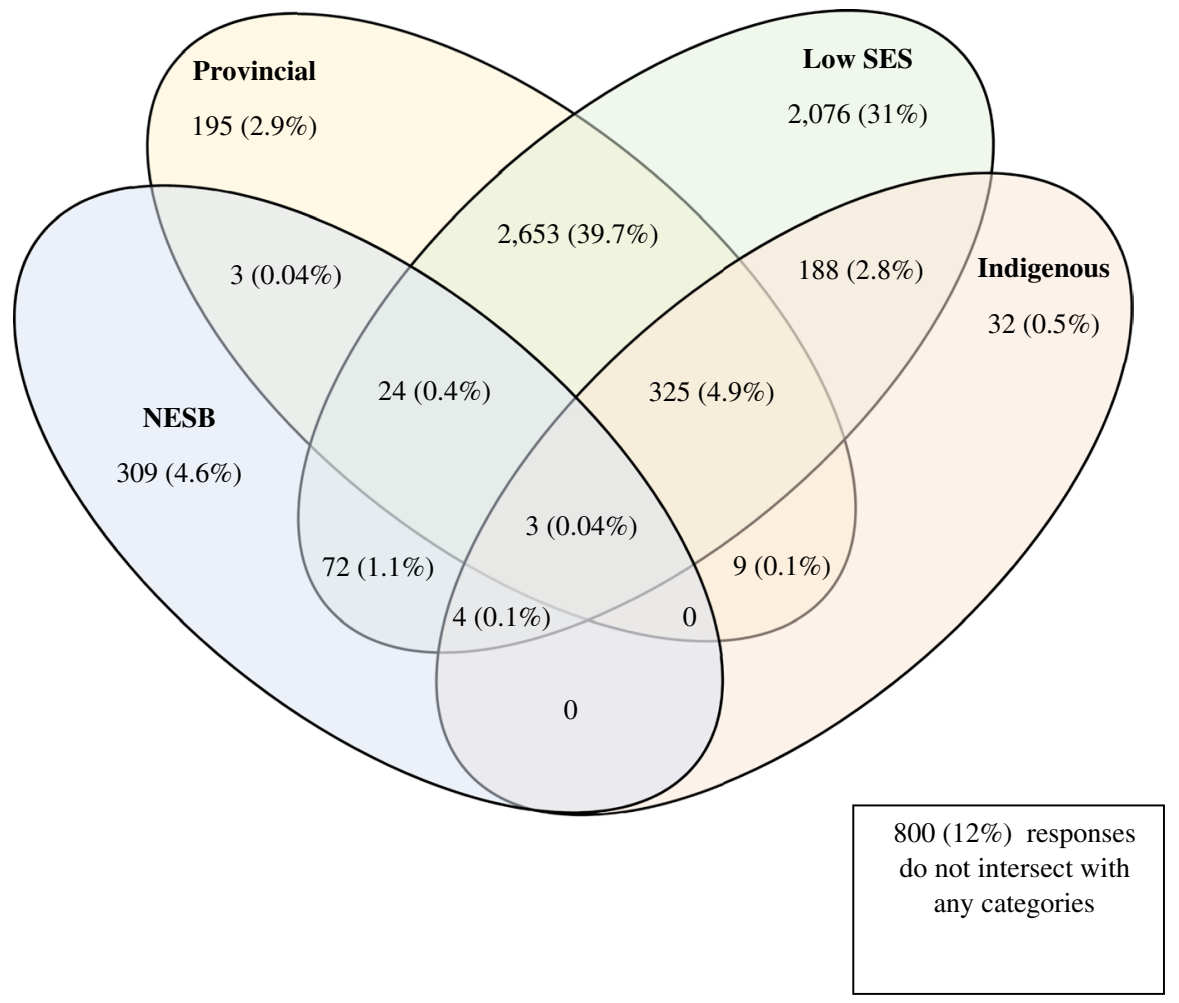

Fig. 1 Socio-demographic intersections, prospective first-generation students

'TAFE' (17.6\%), and 'high school' (15.7\%). For continuing-generation students, the most popular educational aspiration was 'university' $(69.3 \%)$, followed by 'don't know' (20.1\%), 'TAFE' (5.7\%), and 'high school' (4.9\%).

To take into account the cohort-sequential, or accelerated longitudinal, design of the data, Fig. 3 illustrates the proportion of prospective first-generation and continuing-generation students who aspire to university across each year level. This diagram combines data for the four cohorts of students into an overall percentage of first-generation and continuing-generation university aspirants per Year level.

These data show that prospective first-generation students were less likely to aspire to university at all time points captured, from Year 3 to Year 12 inclusive. Year 3 represented the time point when the overall proportion of students aspiring 


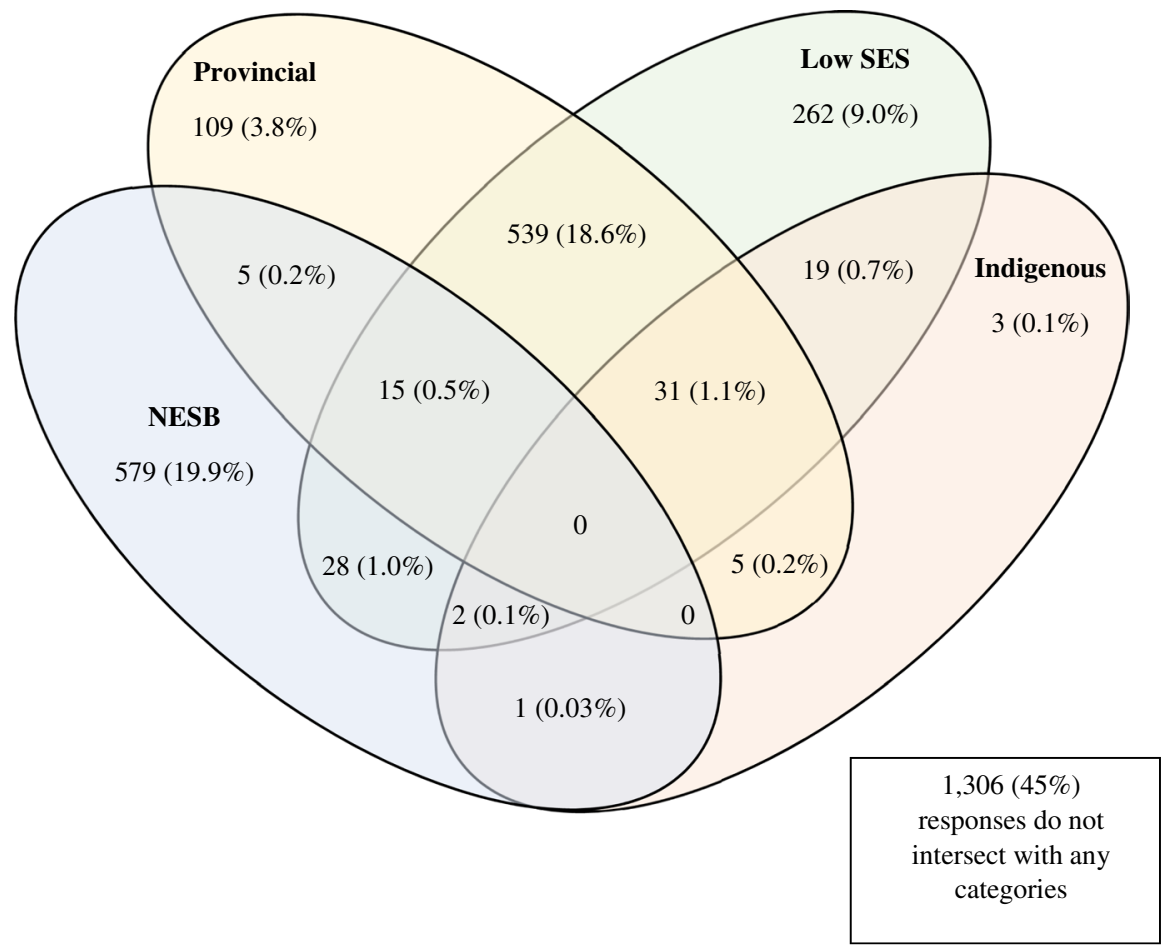

Fig. 2 Socio-demographic intersections, continuing-generation students

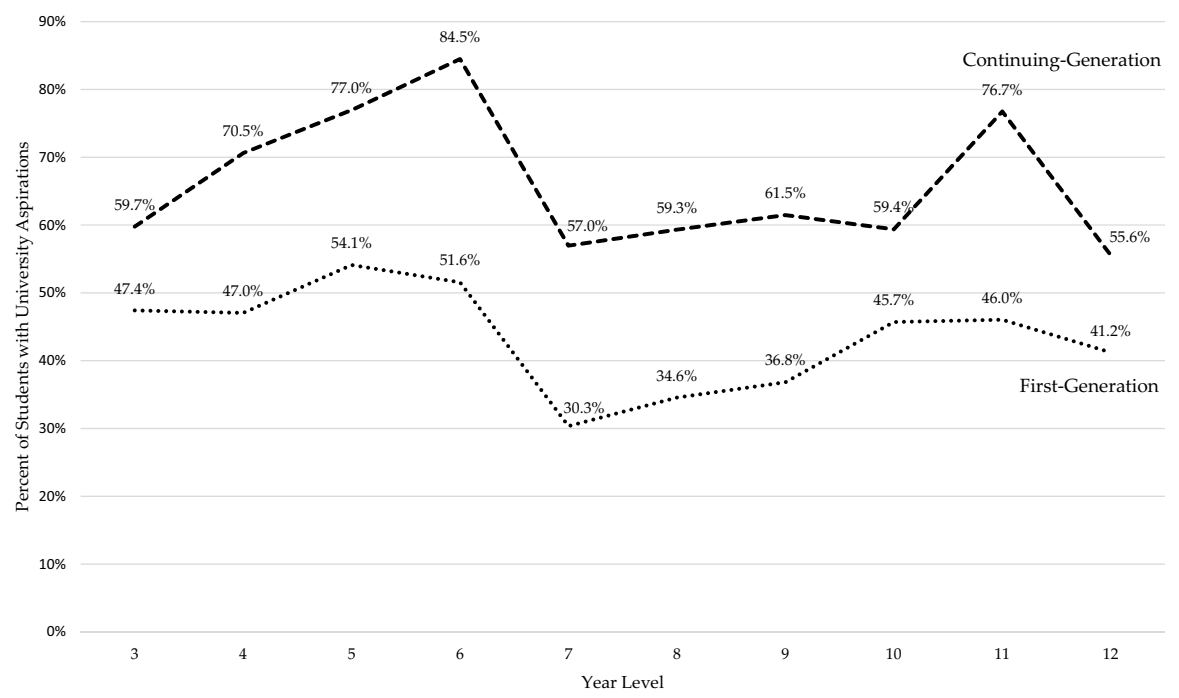

Fig. 3 Overall percentage of students with university aspirations 
to university was most similar. The overall proportion of continuing-generation students aspiring to university increased steadily in the subsequent years of primary school, while the proportion of first-generation students aspiring to university remained at a similar percentage to that seen among Year 3 students. There was a decline in the proportion of both continuing-generation and first-generation students aspiring to university between the time points of Year 6 and Year 7, the first year of secondary school in NSW. Year 10 represented the time point where the overall proportion of students aspiring to university was at its second closest point between first-generation and continuing-generation students.

\section{Logistic regression analyses}

To more fully interrogate differences between prospective first-generation and continuing-generation students in terms of their educational aspirations, first-generation status was examined as a predictor of university aspirations (yes/no) through logistic regression models. Univariate logistic regression analyses were initially undertaken to examine the association between each variable of interest (including first-generation status) and the outcome separate from other independent variables; these results are reported in Table 3 as unadjusted odds ratios (OR) and associated $p$-values. Second, a logistic regression model fitted within a GEE framework examined first-generation status in the presence of other independent variables as potential predictors, reported in Table 3 as adjusted odds ratios and adjusted $p$-values.

Table 3 Logistic regression results

\begin{tabular}{|c|c|c|c|c|c|c|}
\hline \multirow[t]{2}{*}{ Characteristic } & \multicolumn{2}{|c|}{ University aspirations ${ }^{\mathrm{a}}$} & \multicolumn{2}{|c|}{ Univariate models } & \multicolumn{2}{|l|}{ Full model } \\
\hline & Yes, $n(\%)$ & No, $n(\%)$ & Unadjusted OR & $95 \% \mathrm{CI}$ & Adjusted OR & $95 \% \mathrm{CI}$ \\
\hline \multicolumn{7}{|c|}{ First generation status } \\
\hline $\mathrm{Yes}^{\mathrm{b}}$ & $2798(42.5)$ & $3788(57.5)$ & & & & \\
\hline No & $1998(69.3)$ & $885(30.7)$ & $3.04 * * *$ & {$[2.73-3.38]$} & $1.61 * * *$ & [1.41-1.85] \\
\hline \multicolumn{7}{|l|}{ Sex } \\
\hline Male $^{b}$ & 2355 (47.2) & $2637(52.8)$ & & & & \\
\hline Female & $2659(53.9)$ & $2276(46.1)$ & $1.30 * * *$ & [1.19-1.43] & $1.32 * * *$ & [1.18-1.48] \\
\hline \multicolumn{7}{|l|}{ Indigenous status } \\
\hline $\begin{array}{l}\text { Non-Indige- } \\
\text { nous }^{\mathrm{b}}\end{array}$ & $4720(51.4)$ & $4471(48.6)$ & & & & \\
\hline Indigenous & $250(38.6)$ & $397(61.4)$ & $0.62 * * *$ & {$[0.51-0.75]$} & 1.09 & [0.87-1.37] \\
\hline \multicolumn{7}{|c|}{ Language background } \\
\hline English $^{\mathrm{b}}$ & 4285 (48.4) & $4561(51.6)$ & & & & \\
\hline $\begin{array}{l}\text { Non-English } \\
\text { speaking back- } \\
\text { ground }\end{array}$ & 729 (67.4) & $352(32.6)$ & $2.24 * * *$ & [1.92-2.60] & $1.28^{*}$ & [1.03-1.59] \\
\hline
\end{tabular}


Table 3 (continued)

\begin{tabular}{|c|c|c|c|c|c|c|}
\hline \multirow[t]{2}{*}{ Characteristic } & \multicolumn{2}{|c|}{ University aspirations $^{\mathrm{a}}$} & \multicolumn{2}{|c|}{ Univariate models } & \multicolumn{2}{|l|}{ Full model } \\
\hline & Yes, $n(\%)$ & No, $n(\%)$ & Unadjusted OR & $95 \% \mathrm{CI}$ & Adjusted OR & $95 \% \mathrm{CI}$ \\
\hline \multicolumn{7}{|l|}{ Location } \\
\hline Metropolitan $^{\mathrm{b}}$ & $3191(53.4)$ & $2790(46.6)$ & & & & \\
\hline Provincial & $2019(46.1)$ & $2363(53.9)$ & $0.73 * * *$ & {$[0.67-0.80]$} & $1.21 * *$ & [1.06-1.38] \\
\hline \multicolumn{7}{|l|}{ ICSEA } \\
\hline Quartile $1^{b}$ & $1073(42.5)$ & $1453(57.5)$ & & & & \\
\hline Quartile 2 & $1742(41.5)$ & $2459(58.5)$ & 0.92 & {$[0.82-1.03]$} & 0.92 & {$[0.79-1.06]$} \\
\hline Quartile 3 & $610(57.0)$ & $460(43.0)$ & $1.64 * * *$ & [1.39-1.93] & $1.57 * * *$ & [1.25-1.96] \\
\hline Quartile 4 & 1785 (69.6) & $781(30.4)$ & $2.99 * * *$ & {$[2.63-3.40]$} & $1.65 * * *$ & [1.33-2.03] \\
\hline \multicolumn{7}{|l|}{ Cultural capital } \\
\hline Quartile $1^{\mathrm{b}}$ & $902(36.1)$ & $1594(63.9)$ & & & & \\
\hline Quartile 2 & $1140(46.5)$ & $1313(53.5)$ & $1.43 * * *$ & [1.28-1.60] & 1.11 & {$[0.97-1.27]$} \\
\hline Quartile 3 & $1426(55.7)$ & $1133(44.3)$ & $1.97 * * *$ & {$[1.77-2.21]$} & $1.36^{* * *}$ & [1.18-1.57] \\
\hline Quartile 4 & $1606(64.9)$ & $869(35.1)$ & $2.84 * * *$ & [2.53-3.19] & $1.77 * * *$ & [1.53-2.06] \\
\hline \multicolumn{7}{|c|}{ Prior academic achievement } \\
\hline Quartile $1^{\mathrm{b}}$ & $549(28.4)$ & $1383(71.6)$ & & & & \\
\hline Quartile 2 & $960(39.4)$ & $1475(60.6)$ & $1.66^{* * *}$ & {$[1.45-1.90]$} & $1.50 * * *$ & {$[1.27-1.76]$} \\
\hline Quartile 3 & $1503(56.6)$ & $1152(43.4)$ & $3.16^{* * *}$ & {$[2.75-3.62]$} & $2.21 * * *$ & {$[1.86-2.61]$} \\
\hline Quartile 4 & $1908(71.3)$ & $768(28.7)$ & $5.81^{* * *}$ & {$[5.04-6.70]$} & $2.68 * * *$ & {$[2.21-3.24]$} \\
\hline \multicolumn{7}{|c|}{ Self-perception of relative academic performance } \\
\hline $\begin{array}{c}\text { Well below } \\
\text { average }^{\text {b }}\end{array}$ & $50(25.9)$ & $143(74.1)$ & & & & \\
\hline Below average & $175(29.0)$ & $429(71.0)$ & 1.10 & {$[0.77-1.57]$} & 1.18 & {$[0.78-1.81]$} \\
\hline Average & $1599(40.6)$ & $2335(59.4)$ & $1.83^{* * *}$ & {$[1.33-2.52]$} & 1.41 & [0.97-2.06] \\
\hline Above average & 2062 (66.6) & $1034(33.4)$ & $4.58 * * *$ & [3.32-6.32] & $2.76^{* * * *}$ & [1.88-4.06] \\
\hline $\begin{array}{c}\text { Well above } \\
\text { average }\end{array}$ & 892 (71.0) & $365(29.0)$ & $5.23 * * *$ & [3.74-7.31] & $2.86^{* * * *}$ & [1.91-4.28] \\
\hline \multicolumn{7}{|l|}{ Survey year } \\
\hline $2012^{b}$ & $1250(49.0)$ & $1299(51.0)$ & & & & \\
\hline 2013 & $2041(52.2)$ & $1872(47.8)$ & $1.17 * * *$ & [1.08-1.27] & $1.27 * * *$ & [1.12-1.43] \\
\hline 2014 & $903(48.0)$ & $980(52.0)$ & 1.08 & [0.97-1.20] & $1.23 * *$ & [1.06-1.42] \\
\hline 2015 & $1016(50.3)$ & $1002(49.7)$ & $1.17^{* *}$ & [1.05-1.30] & $1.39 * * *$ & [1.20-1.61] \\
\hline \multicolumn{7}{|l|}{ Cohort } \\
\hline Cohort $1^{b}$ & $1696(58.9)$ & $1183(41.1)$ & & & & \\
\hline Cohort 2 & $1529(53.3)$ & 1339 (46.7) & $0.84 * *$ & {$[0.75-0.95]$} & 0.95 & [0.81-1.11] \\
\hline Cohort 3 & $1167(41.3)$ & $1657(58.7)$ & $0.51 * * *$ & {$[0.45-0.58]$} & $0.70 * * *$ & {$[0.59-0.83]$} \\
\hline Cohort 4 & 787 (45.7) & $934(54.3)$ & $0.61 * * *$ & {$[0.53-0.70]$} & 0.90 & [0.74-1.09] \\
\hline
\end{tabular}

OR odds ratio, CI confidence interval

${ }^{\mathrm{a}}$ Based on the number of valid survey responses over the four waves of data collection

${ }^{\mathrm{b}}$ Reference category. ${ }^{*} p<.05$. ${ }^{* *} p<.01$. *** $p<.001$ 
In the univariate analyses, the following variables were significantly related to university aspirations: first-generation status; sex; Indigenous status; language background; location; ICSEA; cultural capital; self-perception of relative academic performance; survey year; and, cohort. Of particular relevance to this paper, continuing-generation students had just over three times the odds of aspiring to university than their prospective first-generation peers (OR 3.04).

In the presence of the other variables in the full model, the variables significantly related to university aspirations were: first-generation status; sex; location, ICSEA; cultural capital; prior academic achievement; self-perception of relative academic performance; survey year; and, cohort. Specifically, we found that continuing-generation students were significantly more likely to aspire to university than first-generation students; continuing-generation students had just over 1.6 times the odds of aspiring to university than their prospective first-generation peers (OR 1.61).

\section{Discussion}

With six equity target groups dominating the Australian higher education policy landscape for thirty years, this paper is a timely investigation of the need for a new group being incorporated into the national equity framework. On the one hand, the current framework has provided a sound grounding for Australian equity policy and practice; a breadth and depth that is unique on the international stage (Coates and Krause 2005). On the other hand, new approaches to addressing equity are needed to ensure funding and other resources are appropriately targeted, and any new interventions take account of emerging insights about educational disadvantage (Harvey et al. 2016). Complementing previous research which has proposed that care leavers (Harvey et al. 2015) and students from refugee backgrounds (Terry et al. 2016) should be added to the framework, we have provided strong evidence that first-generation status warrants inclusion as an official equity target group in future policy reform.

We make our argument in support of first-generation status by returning to Coates and Krause's (2005) three approaches in detail. Drawing on data from the OECD (2012), we began by illustrating the extent to which first-generation students are underrepresented in Australian higher education, showing that enrolment share is far from population parity. Given that equity is understood as "proportional representation' in Australian higher education policy, these figures provide an important foundation for including first-generation status as a targeted equity group, with university access continuing to be strongly associated with parental education despite the move to mass higher education.

Analysis of our own empirical data built on this evidence by demonstrating that first-generation status intersects with the existing equity categories-addressing the second approach from Coates and Krause (2005). It has long been acknowledged that disadvantaged social groups often overlap (Department of Employment, Education and Training 1990) and that it is this 'multiple membership' that can be the locus of greater disadvantage (James et al. 2004). Our findings signal the immense 
potential of first-generation status in capturing this locus of disadvantage. In particular, we found that prospective first-generation students are significantly more likely to identify as Indigenous and come from a lower SES background than their continuing-generation peers. Indeed, students from lower SES backgrounds often have limited family experience of higher education (Bok 2010), while the experiences of Indigenous students are compounded by the historical exclusions placed on Indigenous Australians in the education system. However, first-generation status is not synonymous with these groups, which means that a constrained focus on the current equity framework has potentially disregarded another form of educational disadvantage - the fact that so many young people do not have access to parents/carers with firsthand experience of university. This point is even more important given that we also found that some first-generation students do not fit into any of existing equity categories at all; students who are likely to face challenges associated with 'being first' but who will be overlooked in interventions based on the current target groupings.

Our Venn diagrams further illustrate a matrix of overlapping equity factors for first-generation students, more so than their continuing-generation peers. However, there are two important caveats to point out from this analysis. First, although people from non-English speaking backgrounds prevail as an equity target group, we found that prospective first-generation students are more likely to come from English-speaking backgrounds than their continuing-generation peers. This finding is particularly unique to the Australian context, diverging from US research which has shown that first-generation students are more likely to belong to racial or ethnic minority groups (Engle and Tinto 2008). In addition, while our descriptive analyses showed that many first-generation students live in regional and remote areas, we found no significant differences in relation to the geographic profile of first-generation and continuing-generation students. While this finding could be interpreted to mean that first-generation status does not overlap with rurality, it must be interpreted in light of the geographic location of schools in our sample, which are situated mainly in coastal regions. Population data from the Australian Bureau of Statistics (2008) already point to the fact that there is a lower proportion of Australian adults with a tertiary-level qualification in rural and remote areas, which means that we would expect to see this pattern reflected among young people if our sample included more geographically diverse schools.

We specifically addressed the educational disadvantage of students - the third approach from Coates and Krause (2005)_by examining young people's educational aspirations. Starkly, we found that across every stage of schooling covered in our research (Year 3-12), prospective first-generation students were less likely to aspire to university than their continuing-generation peers. To our knowledge, such a wide age-range has not been examined in previous international studies (Bui and Rush 2016) or in Australia. Our findings therefore provide unique insight into educational disparities associated with first-generation status from a very young age. Indeed, the extent of influence of first-generation status on educational aspirations was illustrated in the regression models, which showed a significant positive association between parental education and aspirations for higher education-a relationship that held even after taking into account the effect of other factors closely tied to 
the existing equity target groups and other markers of (dis)advantage. Of particular note, the effect of first-generation status on educational aspirations was as large as the effect of socio-economic status, represented in this paper by school ICSEA.

Collectively, our findings provide a strong case for first-generation status being recognised within the national equity framework as discrete from the existing equity categories. While first-generation status cuts across many of the existing target groups, its intersection with these groups is both partial and complex. Moreover, given clear differences between the educational aspirations of first-generation students and their continuing-generation peers, first-generation status functions as a form of disadvantage not currently captured in policy. As such, in the context of a university sector that has shifted from 'elite' participation to one 'for the masses', first-generation status can be seen as representing a different struggle for access to higher education (Patfield et al. 2020b); the struggle associated with being a 'newcomer' and the challenges involved in disrupting one's family's educational history (King et al. 2015). This requires additional work that those with university-educated parents are unlikely to experience.

Borrowing from the work of Ahmed (2012), first-generation status can therefore be viewed as a new 'mode of thought' about equity in Australian higher education, outside the confines of what has traditionally been valued in institutionalised, bureaucratic or performance terms. With research into first-generation status growing in Australia (King et al. 2015; O'Shea 2015; O'Shea et al. 2017), and universities beginning to implement 'first-gen' events for incoming students (Patfield et al. 2020a), our study provides rigorous empirical evidence that this relatively new approach to equity in Australia is headed in the right direction. However, greater recognition of this population must not only occur once students have arrived at university, but also during the period of early aspiration formation, over the course of primary and secondary schooling. A critical task for policymakers and practitioners is to ensure that prospective first-generation students are supported to access university (Patfield et al. 2020a, b); an important first step in supporting the success of first-generation university students during their enrolment.

While currently sitting outside the confines of the national equity framework, our analysis demonstrates that first-generation status represents an important aspect of equitable access to higher education. While our research does not provide evidence to argue for the removal of any of the existing equity categories from the national framework, we implore policymakers to consider how the category of first-generation status might be used to identify and target educational disadvantage in a new light to achieve equitable access for more students. Recognising and supporting young people who are taking the momentous step in 'being first', we argue, is a critical component of addressing equity in contemporary higher education.

Acknowledgements The authors wish to thank Dr Felicia Jaremus for her assistance with the preparation of the Figures presented in this paper. We are most grateful for the students, their parents/carers, and teachers who participated in this study.

Funding The research reported on in this paper was supported by an Australian Postgraduate Award. Funding for the larger project was provided by the Australian Research Council and the NSW Department of Education. 
Open Access This article is licensed under a Creative Commons Attribution 4.0 International License, which permits use, sharing, adaptation, distribution and reproduction in any medium or format, as long as you give appropriate credit to the original author(s) and the source, provide a link to the Creative Commons licence, and indicate if changes were made. The images or other third party material in this article are included in the article's Creative Commons licence, unless indicated otherwise in a credit line to the material. If material is not included in the article's Creative Commons licence and your intended use is not permitted by statutory regulation or exceeds the permitted use, you will need to obtain permission directly from the copyright holder. To view a copy of this licence, visit http://creativecommons.org/licen ses/by/4.0/.

\section{References}

Archer, L., DeWitt, J., \& Wong, B. (2013). Spheres of influence: What shapes young people's aspirations at age 12/13 and what are the implications for education policy? Journal of Education Policy, 29, 58-85. https://doi.org/10.1080/02680939.2013.790079.

Ahmed, S. (2012). On being included: Racism and diversity in instituional life. Durham, UK: Duke University Press.

Australian Bureau of Statistics. (2008). Education across Australia. Retrieved from http://www.abs. gov.au.

Ballinger, G. A. (2004). Using generalized estimating equations for longitudinal data analysis. Organizational Research Methods, 7, 127-150. https://doi.org/10.1177/1094428104263672.

Bennett, A., Naylor, R., Mellor, K., Brett, M., Gore, J., Harvey, A., et al. (2015). The critical interventions framework part 2: Equity initiatives in Australian higher education: A review of evidence of impact. Newcastle, Australia: The University of Newcastle. Retrieved from http://www.newca stle.edu.au/_data/assets/pdf_file/0016/261124/REPORT-FINAL.pdf.

Bok, J. (2010). The capacity to aspire to higher education: 'It's like making them do a play without a script.' Critical Studies in Education, 51, 163-178. https://doi.org/10.1080/175084810037310 42.

Bradley, D., Noonan, P., Nugent, H., \& Scales, B. (2008). Review of Australian higher education: Final report. Canberra, Australia: Department of Education, Employment and Workplace Relations. Retrieved from http://hdl.voced.edu.au/10707/44384.

Bui, K., \& Rush, R. A. (2016). Parental involvement in middle school predicting college attendance for first-generation students. Education, 136, 473-489.

Coates, H., \& Krause, K.-L. (2005). Investigating ten years of equity policy in Australian higher education. Journal of Higher Education Policy and Management, 27, 35-47. https://doi. org/10.1080/13600800500045810.

Department of Employment, Education and Training. (1990). A fair chance for all. National and institutional planning for equity in higher education: A discussion paper. Canberra, Australia: Australian Government Publishing Service. Retrieved from http://hdl.voced.edu.au/10707/152620.

Engle, J., \& Tinto, V. (2008). Moving beyond access: College success for low-income, first-generation students. Washington, DC: The Pell Institute for the Study of Opportunity in Higher Education. Retrieved from http://www.pellinstitute.org/publications-Moving_Beyond_Access_2008.shtml.

Gale, T., \& Parker, S. (2013). Widening participation in Australian higher education: Report submitted to the Higher Education Funding Council of England (HEFCE) and the Office of Fair Access (OFFA). Leicester, United Kingdom: CFE Research. Retrieved from http://www.ncsehe.edu.au.

Gore, J., Patfield, S., Holmes, K., Smith, M., Lloyd, A., Gruppetta, M., et al. (2017). When higher education is possible but not desirable: Widening participation and the aspirations of Australian Indigenous school students. Australian Journal of Education, 61, 164-183. https://doi. org/10.1177/0004944117710841.

Gore, J., Patfield, S., Holmes, K., \& Smith, M. (2018). Widening participation in medicine? New insights from school students' aspirations. Medical Education, 52, 227-238. https://doi. org/10.1111/medu.13480.

Harvey, A., McNamara, P., Andrewartha, L., \& Luckman, M. (2015). Out of care, into university: Raising higher education access and achievement of care leavers. Perth, Australia: National 
Centre for Student Equity in Higher Education, Curtin University. Retrieved from https://www. ncsehe.edu.au.

Harvey, A., Burnheim, C., \& Brett, M. (2016). Towards a fairer chance for all: Revising the Australian student equity framework. In A. Harvey, C. Burnheim, \& M. Brett (Eds.), Student equity in Australian higher education: Twenty-five years of a fair chance for all (pp. 3-20). Singapore, Singapore: Springer.

Harwood, V., McMahon, S., O’Shea, S., Bodkin-Andrews, G., \& Priestly, A. (2015). Recognising aspiration: The AIME program's effectiveness in inspiring Indigenous young people's participation in schooling and opportunities for further education and employment. The Australian Educational Researcher, 42, 217-236. https://doi.org/10.1007/s13384-015-0174-3.

Hawkins, C. (2014). The graduate, the globetrotter and the good samaritan: Adolescent girls' visions of themselves in early adulthood. The Australian Educational Researcher, 41, 565-583. https://doi. org/10.1007/s13384-014-0149-9.

James, R., Baldwin, G., Coates, H., Krause, K.-L., \& McInnis, C. (2004). Analysis of equity groups in higher education 1991-2002. Melbourne, Australia: Centre for the Study of Higher Education, The University of Melbourne. Retrieved from http://melbourne-cshe.unimelb.edu.au/research/researchprojects/equity/analysis-of-equity-groups.

Jehangir, R. R. (2010). Higher education and first-generation students: Cultivating community, voice, and place for the new majority. New York: Palgrave Macmillan. https://doi.org/10.1057/97802 30114678.

King, S., Luzeckyj, A., McCann, B., \& Graham, C. (2015). Exploring the experience of being first in family at university: A 2014 student equity in higher education research grants project. Perth, Australia: National Centre for Student Equity in Higher Education, Curtin University. Retrieved from https:// www.ncsehe.edu.au.

Koshy, P. (2019). Equity student participation in Australian higher education: 2013-2018. Perth, Australia: National Centre for Student Equity in Higher Education, Curtin University. Retrieved from https://www.ncsehe.edu.au.

Luzeckyj, A., McCann, B., Graham, C., King, S., \& McCann, J. (2017). Being first in family: Motivations and metaphors. Higher Education Research \& Development, 36, 1237-1250. https://doi. org/10.1080/07294360.2017.1300138.

Meuleman, A.-M., Garrett, R., Wrench, A., \& King, S. (2014). 'Some people might say I'm thriving but ... ': Non-traditional students' experiences of university. International Journal of Inclusive Education, 19, 503-517. https://doi.org/10.1080/13603116.2014.945973.

O'Shea, S. (2014). Transitions and turning points: Exploring how first-in-family female students story their transition to university and student identity formation. International Journal of Qualitative Studies in Education, 27, 135-158. https://doi.org/10.1080/09518398.2013.771226.

O'Shea, S. (2015). Filling up silences-First in family students, capital and university talk in the home. International Journal of Lifelong Education, 34, 139-155. https://doi.org/10.1080/02601 370.2014.980342.

O'Shea, S., Stone, C., May, J., \& Delahunty, J. (2015). Breaking the barriers: Supporting and engaging mature age first-in-family university learners and their families (PowerPoint slides). Retrieved from http://www.firstinfamily.com.au/teaching.php\#6.

O’Shea, S., May, J., Stone, C., \& Delahunty, J. (2017). First-in-family students, university experience and family life: Motivations, transitions and participation. London, United Kingdom: Palgrave Macmillan.

OECD. (2012). Education at a glance 2012: OECD indicators. Paris, France: OECD Publishing.

Patfield, S., Gore, J., \& Fray, L. (2020a). Degrees of 'being first': Toward a nuanced understanding of first-generation entrants to higher education. Educational Review. https://doi.org/10.1080/00131 911.2020.1740172.

Patfield, S., Gore, J., \& Fray, L. (2020b). Reframing first-generation entry: How the familial habitus shapes aspirations for higher education among prospective first-generation students. Higher Education Research \& Development. https://doi.org/10.1080/07294360.2020.1773766.

Pitman, T. (2017). Widening participation in higher education: A play in five acts. Australian Universities' Review, 59, 37-46.

Spiegler, T., \& Bednarek, A. (2013). First-generation students: What we ask, what we know and what it means: An international review of the state of research. International Studies in Sociology of Education, 23, 318-337. https://doi.org/10.1080/09620214.2013.815441. 
Terry, L., Naylor, R., Nguyen, N., \& Rizzo, A. (2016). Not there yet. An investigation into the access and participation of students from humanitarian refugee backgrounds in the Australian higher education system. Melbourne, Australia: Centre for the Study of Higher Education, The University of Melbourne. Retrieved from https://www.ncsehe.edu.au.

Zeger, S. L., Liang, K.-Y., \& Albert, P. S. (1988). Models for longitudinal data: A generalized estimating equation approach. Biometrics, 44, 1049-1060. https://doi.org/10.2307/2531734.

Publisher's Note Springer Nature remains neutral with regard to jurisdictional claims in published maps and institutional affiliations.

Dr. Sally Patfield is a Postdoctoral Fellow in the Teachers and Teaching Research Centre at the University of Newcastle. Sally has over 15 years' experience working in various educational contexts, including as a classroom teacher in NSW public schools, in arts education, and across professional and academic roles in higher education. Sally's doctoral research investigated school students who would be the first in their families to enter higher education, which was awarded the Ray Debus Award for Doctoral Research in Education by the Australian Association for Research in Education.

Jennifer Gore is Director, Teachers and Teaching Research Centre and Head of the Quality Teaching Academy at the University of Newcastle and Visiting Professor at the University of Oxford. Her research focuses on quality and equity, teacher development, pedagogical reform, and enhancing student outcomes. Her current agenda focuses on the impact of Quality Teaching Rounds on teachers and students and the formation of educational aspirations during schooling.

Dr. Natasha Weaver is a lecturer in Biostatistics in the School of Medicine and Public Health at the University of Newcastle. She teaches introductory biostatistics to large cohorts of postgraduate students and was an instrumental part of designing curriculum for the new online Master of Medical Statistics program. In the research part of her role she provides consultation regarding study design, methodology, and analysis for clinicians and researchers within the University and affiliated local health district. 